\title{
Detection of exostosin glycosyltransferase gene mutations in patients with non-hereditary osteochondromas of the mandibular condyle
}

\author{
QIN ZHOU ${ }^{1}$, CHI YANG ${ }^{1}$, MIN-JIE CHEN ${ }^{1}$ and LING-ZHI LI ${ }^{2}$ \\ ${ }^{1}$ Department of Oral and Maxillofacial Surgery, Ninth People's Hospital, Shanghai Key Laboratory of Stomatology, \\ Shanghai Jiao Tong University School of Medicine, Shanghai 200011; ${ }^{2}$ Department of Stomatology, \\ Huashan Hospital, Fudan University, Shanghai 200438, P.R. China
}

Received June 23, 2015; Accepted January 20, 2016

DOI: $10.3892 / \operatorname{mco} .2016 .955$

\begin{abstract}
Exostosin glycosyltransferase (EXT) 1 and EXT2 have been identified as causative genes in osteochondroma; however, it is not known whether these genes are also involved in condylar osteochondromas. The aim of this study was to identify EXT1 and EXT2 mutations in patients with non-hereditary osteochondromas of the mandibular condyle. DNA was obtained from resected tissues (cartilage cap) of 12 patients with solitary condylar osteochondromas. The exons, 3',5'-untranslated regions and intron-exon boundaries of EXT1 and EXT2 were amplified by polymerase chain reaction and the products were sequenced directly. Through direct sequencing, four genetic variations of EXT1 in 4 cases and three variations of EXT2 in 5 cases were identified. The intronic alteration of the EXT2 gene, occurring in 2 cases, was novel, whereas the other alterations had been previously reported. Nonsense somatic mutations were detected in tumor DNA. Our study extended the mutational spectrum in EXT1 and EXT2 and may facilitate a better understanding of the pathophysiology of condylar osteochondromas.
\end{abstract}

\section{Introduction}

Osteochondroma is a cartilage-capped bony projection arising from the external surface of bone, containing a marrow cavity that is continuous with that of the underlying bone (1). Osteochondroma is the most common benign bone tumour,

Correspondence to: Professor Chi Yang or Professor Min-Jie Chen, Department of Oral and Maxillofacial Surgery, Ninth People's Hospital, Shanghai Key Laboratory of Stomatology, Shanghai Jiao Tong University School of Medicine, 639 Zhi Zao Ju Road, Shanghai 200011, P.R. China

E-mail: yangchi63@hotmail.com

E-mail: chenminjie00@126.com

Key words: exostosin glycosyltransferases 1 and 2, mutation, condylar osteochondroma mainly arising in the juxta-epiphyseal region of long bones (1). Approximately $15 \%$ of osteochondromas occur in the context of multiple osteochondromas (MO), previously referred to as hereditary multiple exostoses, which is an autosomal dominantly inherited disorder $(2,3)$, while the majority of osteochondromas present as solitary (non-hereditary) lesions. Solitary and multiple osteochondromas are histologically indistinguishable (4). Osteochondromas have been associated with defects in the exostosin glycosyltransferase (EXT) 1 gene on chromosome 8q24.11-q24.13 (MIM 608177) and EXT2 on chromosome 11p12-p11 (MIM 608210) (5-7).

Osteochondroma may be an incidental finding, or diagnosed due to secondary events, such as esthetic or mechanical problems. Osteochondromas of the mandibular condyle have been associated with facial asymmetry, preauricular pain or edema, occlusal disorders, limitation of mouth opening, even condylar neck fracture. The most severe complication is malignant transformation into chondrosarcoma. According to Roychoudhury et al (8), by 2011 at least 108 cases had been reported in the English-language literature; those studies were mainly focused on clinical reports, such as clinical manifestations, radiological findings, treatment and prognosis, whereas the study on pathogenesis and molecular biology remains at the initial stage. However, it is not known whether the EXT genes are also involved in condylar osteochondromas. We performed a mutation analysis of the EXT1 and EXT2 genes in 12 cases of solitary osteochondroma of the condyle, to estimate the distribution of mutations that lead to the development of condylar osteochondromas.

\section{Patients and methods}

Patients. A total of 12 sporadic patients diagnosed with condylar osteochondroma were included in this study. Patients with a solitary osteochondroma were selected based on a review of their pathological, clinical and radiological data. After obtaining written informed consent, cartilage from the cap of the resected specimens was collected from each participant. The patients comprised 5 women and 7 men, with a mean age of 45.08 years (range, 23-76 years). The clinical characteristics of all the patients are summarised in Table I. 
Table I. Characteristics of 12 condylar osteochondroma patients.

\begin{tabular}{ccccll}
\hline Case & Gender & $\begin{array}{c}\text { Age } \\
\text { (years })\end{array}$ & Side & $\begin{array}{c}\text { Duration of } \\
\text { symptoms }\end{array}$ & \\
\hline 1 & M & 44 & Right & $>3$ years & Facial asymmetry, LMO, occlusal disorder \\
2 & F & 76 & Right & 3 years & Facial asymmetry, LMO, occlusal disorder, pain \\
3 & M & 49 & Left & 1 months & Facial asymmetry, pain, clicking, occlusal disorder \\
4 & M & 65 & Right & 6 months & Numbness of right tongue base, pain, occlusal disorder \\
5 & M & 50 & Right & 8 months & Facial asymmetry, clicking, occlusal disorder \\
6 & F & 24 & Left & 4 months & Facial asymmetry, occlusal disorder \\
7 & M & 23 & Left & 2 years & Facial asymmetry, occlusal disorder \\
8 & M & 32 & Right & $>5$ years & Facial asymmetry, LMO, pain \\
9 & F & 39 & Left & 7 years & Facial asymmetry, pain, occlusal disorder \\
10 & F & 61 & Left & 2 years & Facial asymmetry, clicking, LMO, occlusal disorder \\
11 & M & 39 & Left & $>2$ years & LMO, pain \\
12 & F & 39 & Right & 2 months & Facial asymmetry \\
\hline
\end{tabular}

M, male; F, female; LMO, limitation of mouth opening.

Table II. Sequencing regions and primers of exostosin glycosyltransferase (EXT) 1 and EXT2 genes.

\begin{tabular}{|c|c|c|c|c|}
\hline Gene & Exon & Sense $\left(5^{\prime}-3^{\prime}\right)$ & Antisense $\left(3^{\prime}-5^{\prime}\right)$ & $\begin{array}{c}\text { Fragment } \\
\text { size } \\
\text { (bp) }\end{array}$ \\
\hline \multirow[t]{13}{*}{ EXT1 } & 1 & CGAGCGCAGGAGTAAACAC & ATTGATCCCAAGGAACGAA & 824 \\
\hline & 1 & GAAAGGCATCCAGAGAAGG & GACTCAGGACAAAGAGGCAC & 614 \\
\hline & 1 & AAAACGGCTTCAAAGTCTACG & TTGCTCAGTTCCAGGCTCA & 768 \\
\hline & 2 & GGGGTGGGGAACAAGAA & GGAACTGAGAGACAATGAAG & 906 \\
\hline & 3 & GAAATGGGGTTTTAGCA & GTTATTGAAAGGGGTGG & 626 \\
\hline & 4 & GAAGTGCTTGGGAGATAA & CGAAGGATGCCATTGAG & 834 \\
\hline & 5 & AGTCTATTTTGGAATGAGC & GAGATATTGGGATTGTGA & 804 \\
\hline & 6 & GCTCTTCCTTTCACCTTT & TCTCTGTAACCCATCCCT & 794 \\
\hline & 7 & CGGACACAGTTGGTTTT & CCACTTTGTAGATGAGGAA & 624 \\
\hline & 8 & GATTTATCTTTGTACCCTCTTTGAC & ATGCAGAACACGCACCC & 675 \\
\hline & 9 & AGATGTGTTTGTGTCTCACG & CCAACTGAAAATGTTACTCTAC & 744 \\
\hline & 10 & GGGAGTAATAATAGAACCTG & CAAATGGACTAAGACAAACT & 711 \\
\hline & 11 & TCAGTTGCTAAGTCGTG & AACAAAGAACTCTGGTTT & 817 \\
\hline \multirow[t]{16}{*}{ EXT2 } & 1 & CGCCTGCCTGGGAAAAC & GGCTAGGAGAACAGGTGGGTA & 548 \\
\hline & 2 & CTGCTGGGTCGGGACAA & GTTCCCACCGAATGTAACAAA & 794 \\
\hline & 3 & TGGTCACAGTTACTTGGG & GGCAGACTACTCTTCACG & 997 \\
\hline & 4 & TAACCAGGCTTCTCTAATG & CGCTACСТTCTCTCAGTAA & 751 \\
\hline & 5 & GGGAAGTAAGGAAAGGGTAT & CTAAGGGCAATGTGAAGC & 815 \\
\hline & 6 & AACTGTTCCCAAATAAGATG & GGGGGTAAAAGCAAGATA & 763 \\
\hline & 7 & AAGGTAGGCTGAGGTAAG & GTAAAGGAAGGGACACG & 776 \\
\hline & 8 & GTAGGGAGTGGGAGGTAAA & AATGGGGTGTCAGAAGGT & 818 \\
\hline & 9 & ACATGGCTATTCTCATCAT & TGCСТССТTAСТTATCTCT & 668 \\
\hline & 10 & GGGTTTGGGGAGAGAAT & GAGCAGAGATAAGAAAGGAGA & 826 \\
\hline & 11 & TTGAAGCCAATTTGTTC & CTTTGTTTGTCAGTGTCG & 877 \\
\hline & 12 & TAATACAAATCAGGGCAGTT & GGCTCACAATACAATCCA & 883 \\
\hline & 13 & TAATGCCTCCTTTTACC & GCCTTTATTCTGATACTGA & 533 \\
\hline & 14 & GAAAGAGGAGAAAGAGCG & CCCTGAAAAATAATCCAGTA & 827 \\
\hline & 15 & САTCTCCTGTTCACGTTCT & GCTGGTGCTCTTCCTGT & 949 \\
\hline & 15 & TGGAGAAGAGAAGCGTGTT & GCAAAGCAGTTGTATAGCAG & 736 \\
\hline
\end{tabular}


Table III. Characters of EXT genetic variations in condylar osteochondroma.

\begin{tabular}{|c|c|c|c|c|c|}
\hline Gene & Case & Genetic variation & Identity in dbSNP & Region & Allele freq \\
\hline \multirow[t]{4}{*}{ EXT1 } & 1 & chr8_118830894_G/A & rs4876757 & Intron & 0.2688 \\
\hline & 2 & chr8_118830820_A/G & rs10955837 & Intron & 0.4446 \\
\hline & 1 & chr8_118834952_G/A & rs4355803 & Intron & 0.2848 \\
\hline & 8 & chr8_118819578_G/A & rs7837891 & Exon 9 & 0.3681 \\
\hline \multirow[t]{5}{*}{ EXT2 } & 3 & chr11_44117372_C/G & rs12800404 & 5'UTR & 0.0403 \\
\hline & 7 & chr11_44117899_G/T & Novel & Intron & - \\
\hline & 12 & chr11_44117899_G/T & Novel & Intron & - \\
\hline & 1 & chr11_44129290_C/A & rs4755228 & Exon 3 & 0.0893 \\
\hline & 2 & chr11_44129290_C/A & rs 4755228 & Exon 3 & 0.0893 \\
\hline
\end{tabular}

EXT, exostosin glycosyltransferase; dbSNP, single-nucleotide polymorphism database; UTR, untranslated region.

\section{CAGGGGCATGT TAT GCCGGGG ACT}

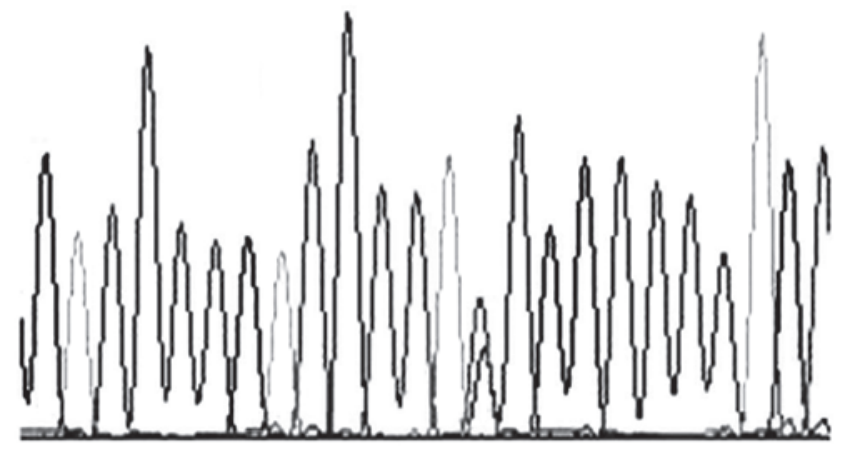

Figure 1. Novel polymorphic loci of exostosin glycosyltransferase 2 in samples 7 and 12 .

Mutation analysis of EXT genes. DNA was extracted from the cartilage cap of resected specimens using the DNeasy Tissue kit (cat. no. 69581; Qiagen). DNA was polymerase chain reaction (PCR)-amplified with 13 pairs of PCR primers for 11 exons, 3',5'-untranslated regions (UTR) and intron-exon boundaries of the EXT1 gene, and 16 pairs for 15 exons, 3',5'-UTRs and intron-exon boundaries of the EXT2 gene (Table II). PCR cycling was performed on the 2720 Thermal Cycler (Applied Biosystems) using the Taq PCR Mastermix kit (Takara Biotechnology). All PCR programs included an initial denaturation of $5 \mathrm{~min}$ at $94^{\circ} \mathrm{C}$, followed by 32 cycles of $15 \mathrm{sec}$ at $94^{\circ} \mathrm{C}, 35 \mathrm{sec}$ at $55-60^{\circ} \mathrm{C}$, and $60 \mathrm{sec}$ at $72^{\circ} \mathrm{C}$; and a final extension step of $5 \mathrm{~min}$ at $72^{\circ} \mathrm{C}$. The products were purified with QIAquick PCR Purification kit (cat. no. 28106; Qiagen) and the purified PCR products were sequenced using the forward and reverse primers. Automated sequencing was performed on an ABI PRISM ${ }^{\circledR}$ 3730XL Genetic Analyzer (Applied Biosystems).

\section{Results}

Genetic variations of EXT1. Through direct sequencing of all exons, intron-exon boundaries and 3',5'-UTRs, four genetic variations of EXT1 were identified, of which one was a synonymous coding variation (chr8_118819578_G/A in case 8), and three were in intronic regions (chr8_118830894_G/A and chr8_118834952_G/A in case 1, and chr8_118830820_A/G in case 2), which have been previously reported (Table III).

Genetic variations of EXT2. Five variations of EXT2 were detected, two of which were synonymous coding variations (chr11_44129290_C/A in cases 1 and 2), two were in intronic regions (chr11_44117899_G/T in cases 7 and 12) and one was in the 5'-UTR (chr11_44117372_C/G in case 3). The genetic variations (chr11_44117899_G/T in cases 7 and 12) in EXT2 were novel (Fig. 1, Table III). All the mutations were confirmed by repeat PCR and sequencing.

\section{Discussion}

Osteochondroma was previously considered as a perversion in the direction of normal bone growth, resulting from aberrant epiphyseal development (9). However, later studies demonstrated that loss or mutation of EXT1 or EXT2 are crucial in the pathogenesis of solitary as well as hereditary osteochondromas $(10,11)$. Germline mutations of either the EXT1 or EXT2 gene may be identified in $>85 \%$ of the analyzed MO cases and MO families (12-16). Approximately 77-80\% of intragenic EXT1 and EXT2 mutations are inactivating mutations (44-66\% associated with EXT1 and 27\% with EXT2) $(16,17)$. These alterations result in truncated (non-functional) EXT proteins $(18,19)$. The protein products of EXT1 and EXT2 are type II transmembrane glycoproteins and comprise a Golgi-localized hetero-oligomeric complex involved in heparan sulphate proteoglycan (HSPG) biosynthesis. Hameetman et al (20) found that EXT1 or EXT2 mRNA expression in osteochondromas was decreased; however, in non-hereditary tumors, only decreased EXT1 mRNA expression was detected. Decreased EXT1 or EXT2 mRNA expression in osteochondromas was associated with intracellular accumulation of HSPGs in the Golgi apparatus. It has been shown that a lack of HSPGs on the cell surface affects growth signaling pathways in the growth plate [e.g., Indian hedgehog (IHH) signaling] and, possibly, those in osteochondromas (21-23). In the growth plate, IHH requires interaction with HSPGs to diffuse through the extracellular matrix to its receptor (21). 
Somatic mutations in the EXT genes are extremely rare in non-hereditary osteochondromas and have been described in only 3 cases (24-26). However, the observation that loss of heterozygosity $(\mathrm{LOH})$ and clonal rearrangement at 8q24 (EXT1 locus) are as frequent in non-hereditary osteochondromas as are EXT1 gene mutations in patients with hereditary osteochondromas, suggests that EXT1 may be involved in the development of non-hereditary osteochondromas $(10,11,27)$. By contrast, $\mathrm{LOH}$ at the EXT2 locus has been reported in only 1 case of non-hereditary osteochondroma (28).

Structural changes in the EXT1 locus have been reported in 10/30 non-hereditary and in 1/13 hereditary osteochondromas $(10,11)$. LOH detected by microsatellite analysis using DNA isolated from the cartilaginous cap was found almost exclusively at the EXT1 locus (27). Fluorescence in situ hybridization revealed loss of the 8q24.1 locus in 27/34 (79\%) osteochondromas (29). Finally, in 7/8 solitary osteochondromas, homozygous deletion of EXT1 was detected (30). Of note, EXT2 was found to be affected only in MO and not in solitary lesions. In our study, we analyzed 12 patients with solitary osteochondroma for the presence of mutations in the EXT1 and EXT2 genes. A novel nonsense mutation (chr11_44117899_G/T in the intronic region in cases 7 and 12) was identified.The other 7 variations were already in the databases. Apart from known polymorphisms, no sense somatic or germline mutations were detected in tumor DNA. The results were consistent with the rarity of EXT gene mutations in non-hereditary osteochondromas. As the LOH and clonal rearrangement in EXT genes are common, we should analyse the incidence of deletions and rearrangement in condylar osteochondromas.

In conclusion, we screened EXT1 and EXT2 mutations in 12 patients with non-hereditary osteochondromas of the mandibular condyle. To the best of our knowledge, this is the first study to identify mutations of EXT1 and EXT2 in condylar osteochondromas. Our study extended the mutational spectrum in EXT1 and EXT2 and may facilitate a better understanding of the pathophysiology of condylar osteochondromas.

\section{References}

1. Khurana J, Abdul-Karim F and Bovée JVMG: Osteochondroma. In: World Health Organization Classification of Tumours. Pathology and Genetics of Tumours of Soft Tissue and Bone. Fletcher CDM, Unni KK and Mertens F (eds.) IARC Press, Lyon, pp234-236, 2002.

2. Wicklund CL, Pauli RM, Johnston D and Hecht JT: Natural history study of hereditary multiple exostoses. Am J Med Genet 55: 43-46, 1995.

3. Bovée JVMG and Hogendoorn PCW: Multiple osteochondromas. In: World Health Organization Classification of Tumours. Pathology and Genetics of Tumours of Soft Tissue and Bone Fletcher CDM, Unni KK and Mertens F (eds.). IARC Press, Lyon, pp360-362, 2002.

4. Hameetman L, Bovée JV, Taminiau AH, Kroon HM and Hogendoorn PC: Multiple osteochondromas: Clinicopathological and genetic spectrum and suggestions for clinical management. Hered Cancer Clin Pract 2: 161-173, 2004.

5. Wu YQ, Heutink P, de Vries BB, Sandkuijl LA, van den Ouweland AM, Niermeijer MF, Galjaard H, Reyniers E, Willems PJ and Halley DJ: Assignment of a second locus for multiple exostoses to the pericentromeric region of chromosome 11. Hum Mol Genet 3: 167-171, 1994.

6. Wuyts W, Ramlakhan S, Van Hul W, Hecht JT, van den Ouweland AM, Raskind WH, Hofstede FC, Reyniers E, Wells DE and de Vries B: Refinement of the multiple exostoses locus (EXT2) to a 3-cM interval on chromosome 11. Am J Hum Genet 57: 382-387, 1995.
7. Lüdecke HJ, Ahn J, Lin X, Hill A, Wagner MJ, Schomburg L, Horsthemke B and Wells DE: Genomic organization and promoter structure of the human EXT1 gene. Genomics 40: 351-354, 1997.

8. Roychoudhury A, Bhatt K, Yadav R, Bhutia O and Roychoudhury S: Review of osteochondroma of mandibular condyle and report of a case series. J Oral Maxillofac Surg 69: 2815-2823, 2011

9. Huvos AG: Bone Tumors. Diagnosis, Treatment and Prognosis. 2nd edition. WB Saunders, Philadelphia, 1991.

10. Mertens F, Rydholm A, Kreicbergs A, Willén H, Jonsson K, Heim S, Mitelman F and Mandahl N: Loss of chromosome band $8 \mathrm{q} 24$ in sporadic osteocartilaginous exostoses. Genes Chromosomes Cancer 9: 8-12, 1994.

11. Bridge JA, Nelson M, Orndal C, Bhatia P and Neff JR: Clonal karyotypic abnormalities of the hereditary multiple exostoses chromosomal loci 8q24.1 (EXT1) and 11p11-12 (EXT2) in patients with sporadic and hereditary osteochondromas. Cancer 82: 1657-1663, 1998.

12. Wuyts W, Van Hul W, De Boulle K, Hendrickx J, Bakker E, Vanhoenacker F, Mollica F, Lüdecke HJ, Sayli BS, Pazzaglia UE, et al: Mutations in the EXT1 and EXT2 genes in hereditary multiple exostoses. Am J Hum Genet 62: 346-354, 1998.

13. Wuyts W, Radersma R, Storm K and Vits L: An optimized DHPLC protocol for molecular testing of the EXT1 and EXT2 genes in hereditary multiple osteochondromas. Clin Genet 68: 542-547, 2005.

14. Lonie L, Porter DE, Fraser M, Cole T, Wise C, Yates L, Wakeling E, Blair E, Morava E, Monaco AP and Ragoussis J: Determination of the mutation spectrum of the EXT1/EXT2 genes in British Caucasian patients with multiple osteochondromas and exclusion of six candidate genes in EXT negative cases. Hum Mutat 27: 1160, 2006.

15. Pedrini E, De Luca A, Valente EM, Maini V, Capponcelli S, Mordenti M, Mingarelli R, Sangiorgi L and Dallapiccola B: Novel EXT1 and EXT2 mutations identified by DHPLC in Italian patients with multiple osteochondromas. Hum Mutat 26: $280,2005$.

16. Jennes I, Pedrini E, Zuntini M, Mordenti M, Balkassmi S, Asteggiano CG, Casey B, Bakker B, Sangiorgi L and Wuyts W: Multiple osteochondromas: Mutation update and description of the multiple osteochondromas mutation database (MOdb). Hum Mutat 30: 1620-1627, 2009.

17. Wuyts W and Van Hul W: Molecular basis of multiple exostoses: Mutations in the EXT1 and EXT2 genes. Hum Mutat 15: 220-227, 2000.

18. McCormick C, Duncan G, Goutsos KT and Tufaro F: The putative tumor suppressors EXT1 and EXT2 form a stable complex that accumulates in the Golgi apparatus and catalyzes the synthesis of heparan sulfate. Proc Natl Acad Sci USA 97: 668-673, 2000.

19. Cheung PK, McCormick C, Crawford BE, Esko JD, Tufaro F and Duncan G: Etiological point mutations in the hereditary multiple exostoses gene EXT1: A functional analysis of heparan sulfate polymerase activity. Am J Hum Genet 69: 55-66, 2001.

20. Hameetman L, David G, Yavas A, White SJ, Taminiau AH, Cleton-Jansen AM, Hogendoorn PC and Bovée JV: Decreased EXT expression and intracellular accumulation of HSPG in osteochondromas and peripheral chondrosarcomas. J Pathol 211: 399-409, 2007.

21. Koziel L, Kunath M, Kelly OG and Vortkamp A: Ext1-dependent heparan sulfate regulates the range of Ihh signaling during endochondral ossification. Dev Cell 6: 801-813, 2004.

22. Hameetman L, Rozeman LB, Lombaerts M, Oosting J, Taminiau AH, Cleton-Jansen AM, Bovée JV and Hogendoorn PC: Peripheral chondrosarcoma progression is accompanied by decreased Indian Hedgehog (IHH) signalling. J Pathol 209: 501-511, 2006.

23. Benoist-Lasselin C, de Margerie E, Gibbs L, Cormier S, Silve C, Nicolas G, LeMerrer M, Mallet JF, Munnich A, Bonaventure J, et al: Defective chondrocyte proliferation and differentiation in osteochondromas of MHE patients. Bone 39: 17-26, 2006.

24. Hecht JT, Hall CR, Snuggs M, Hayes E, Haynes R and Cole WG: Heparan sulfate abnormalities in exostosis growth plates. Bone 31: 199-204, 2002.

25. Bernard MA, Hall CE, Hogue DA, Cole WG, Scott A, Snuggs MB, Clines GA, Lüdecke HJ, Lovett M, Van Winkle WB and Hecht JT: Diminished levels of the putative tumor suppressor proteins EXT1 and EXT2 in exostosis chondrocytes. Cell Motil Cytoskeleton 48: 149-162, 2001. 
26. Hecht JT, Hogue D, Wang Y, Blanton SH, Wagner M, Strong LC, Raskind W, Hansen MF and Wells D: Hereditary multiple exostoses (EXT): Mutational studies of familial EXT1 cases and EXT-associated malignancies. Am J Hum Genet 60: 80-86, 1997.

27. Bovée JV, Cleton-Jansen AM, Wuyts W, Caethoven G, Taminiau AH, Bakker E, Van Hul W, Cornelisse CJ and Hogendoorn PC: EXT-mutation analysis and loss of heterozygosity in sporadic and hereditary osteochondromas and secondary chondrosarcomas. Am J Hum Genet 65: 689-698, 1999.

28. Esko JD and Selleck SB: Order out of chaos: Assembly of ligand binding sites in heparan sulfate. Annu Rev Biochem 71: 435-471, 2002.
29. Feely MG, Boehm AK, Bridge RS, Krallman PA, Neff JR, Nelson M and Bridge JA: Cytogenetic and molecular cytogenetic evidence of recurrent 8q24.1 loss in osteochondroma. Cancer Genet Cytogenet 137: 102-107, 2002.

30. Hameetman L, Szuhai K, Yavas A, Knijnenburg J, van Duin M, van Dekken H, Taminiau AH, Cleton-Jansen AM, Bovée JV and Hogendoorn PC: The role of EXT1 in nonhereditary osteochondroma: Identification of homozygous deletions. J Natl Cancer Inst 99: 396-406, 2007. 